\title{
Deletion of the R78 G Protein-Coupled Receptor Gene from Rat Cytomegalovirus Results in an Attenuated, Syncytium-Inducing Mutant Strain
}

\author{
PATRICK S. BEISSER, GERT GRAULS, CATHRIEN A. BRUGGEMAN, AND CORNELIS VINK* \\ Department of Medical Microbiology, Cardiovascular Research Institute Maastricht, Maastricht University, \\ 6202 AZ Maastricht, The Netherlands
}

Received 22 January 1999/Accepted 20 May 1999

\begin{abstract}
The rat cytomegalovirus (RCMV) R78 gene belongs to an uncharacterized class of viral G protein-coupled receptor (GCR) genes. The predicted amino acid sequence of the $R 78$ open reading frame (ORF) shows 25 and $20 \%$ similarity with the gene products of murine cytomegalovirus M78 and human cytomegalovirus UL78, respectively. The $\mathrm{R} 78$ gene is transcribed throughout the early and late phases of infection in rat embryo fibroblasts (REF) in vitro. Transcription of $R 78$ was found to result in three different mRNAs: (i) a 1.8-kb mRNA containing the $R 78$ sequence, (ii) a 3.7-kb mRNA containing both $R 77$ and $R 78$ sequences, and (iii) a 5.7-kb mRNA containing at least ORF R77 and ORF R78 sequences. To investigate the function of the R78 gene, we generated two different recombinant virus strains: an RCMV R78 null mutant (RCMV $\Delta$ R78a) and an RCMV mutant encoding a GCR from which the putative intracellular $C$ terminus has been deleted (RCMV $\Delta$ R78c). These recombinant viruses replicated with a 10- to 100-fold-lower efficiency than wild-type (wt) virus in vitro. Interestingly, unlike wt virus-infected REF, REF infected with the recombinants develop a syncytium-like appearance. A striking difference between wt and recombinant viruses was also seen in vivo: a considerably higher survival was seen among recombinant virus-infected rats than among RCMV-infected rats. We conclude that the RCMV R78 gene encodes a novel GCR-like polypeptide that plays an important role in both RCMV replication in vitro and the pathogenesis of viral infection in vivo.
\end{abstract}

G protein-coupled receptors (GCRs) play a key role in transduction of extracellular signals to the intracellular environment. They can be activated by a variety of stimuli, such as neurotransmitters, hormones, and photons (reviewed by Probst et al. [53]). Upon ligand binding, GCRs activate G proteins, which in turn activate effector enzymes and ion channels in a cascade-like fashion. Thousands of GCR variants are encoded by genes of both prokaryotes and eukaryotes. Additionally, some are encoded by virus genes. To date, 20 putative viral GCR genes have been discovered: 2 in poxvirus genomes $(21,44), 11$ in betaherpesvirus genomes $(9,22,33,49,54)$, and 7 in gammaherpesvirus genomes $(4,26,48,57,63)$. The majority of these genes was found to be similar to genes encoding cellular chemokine receptors. Although the functions of most of the putative viral GCRs are unclear, several are capable of binding chemokines, hence invoking a classical signal transduction response $(1,4,31,38,42,47)$. The herpesvirus saimiri (HVS) ECRF3-encoded chemokine receptor is capable of transducing signals upon activation by $\alpha$ chemokines (1). The human cytomegalovirus (HCMV) US28-encoded chemokine receptor was shown to be a promiscuous calcium-mobilizing receptor for several $\beta$ chemokines (31). Additionally, the US28 protein was suggested to be responsible for $\beta$-chemokine sequestration in HCMV-infected fibroblasts (15). The GCR encoded by Kaposi's sarcoma-associated herpesvirus (KSHV) open reading frame (ORF) 74 not only binds both $\alpha$ and $\beta$ chemokines but also is constitutively active, inducing secondmessenger signalling in vitro (4). The KSHV chemokine receptor was also shown to stimulate cellular proliferation (4),

\footnotetext{
* Corresponding author. Mailing address: Department of Medical Microbiology, Maastricht University, P.O. Box 5800, 6202 AZ Maastricht, The Netherlands. Phone: 3143 3876669. Fax: 31433876643. E-mail:kvi@lmib.azm.nl.
}

transformation, and angiogenesis (7). A distinctive set of chemokine-like receptors is exclusively encoded by betaherpesviruses: HCMV UL33 (23), rat cytomegalovirus (RCMV) R33 (9), murine cytomegalovirus (MCMV) M33 (54), and human herpesvirus 6 and 7 (HHV-6 and -7) U12 (33, 49). Recently, we found that the RCMV R33 gene is essential for the pathogenesis of viral infection in vivo and that unlike wild-type (wt) virus, an RCMV R33 null mutant could neither enter nor replicate in salivary gland epithelial cells of infected rats (9). A similar observation was made for MCMV M33: upon infection of mice with an MCMV M33 deletion mutant strain, virus could not be recovered from mouse salivary glands (26). Interestingly, betaherpesviruses encode another distinctive set of yet uncharacterized viral GCRs: HCMV UL78 (22), MCMV M78 (54), and HHV-6 and -7 U51 (33, 49). Although the positions of these UL78-like genes within the betaherpesvirus genomes are conserved, their sequences are rather divergent. Despite the presence of distinct GCR characteristics, such as seven transmembrane domains, two conserved cysteine residues, and a G protein-coupling domain (53), these UL78-like gene products show little similarity with any of the thousands of GCRs known to date. Nevertheless, characterization of this unique family of GCRs may be crucial to the development of new antiviral therapeutics. In this report, we present the sequence and transcriptional analysis of the RCMV member of this family of GCR genes, which we termed R78. In addition, RCMV strains were generated in which the R78 (ORF) is either partially or completely deleted from the genome (RCMV $\Delta$ R78a or RCMV $\Delta$ R78c, respectively). We show that disruption of the R78 gene affects RCMV replication in permissive cell types in vitro and that the RCMV R78 deletion mutant strains induce syncytium formation in rat embryo fibroblasts (REF) in vitro, in contrast to wt RCMV. In addition, a dramatically lower mortality was observed in rats infected 


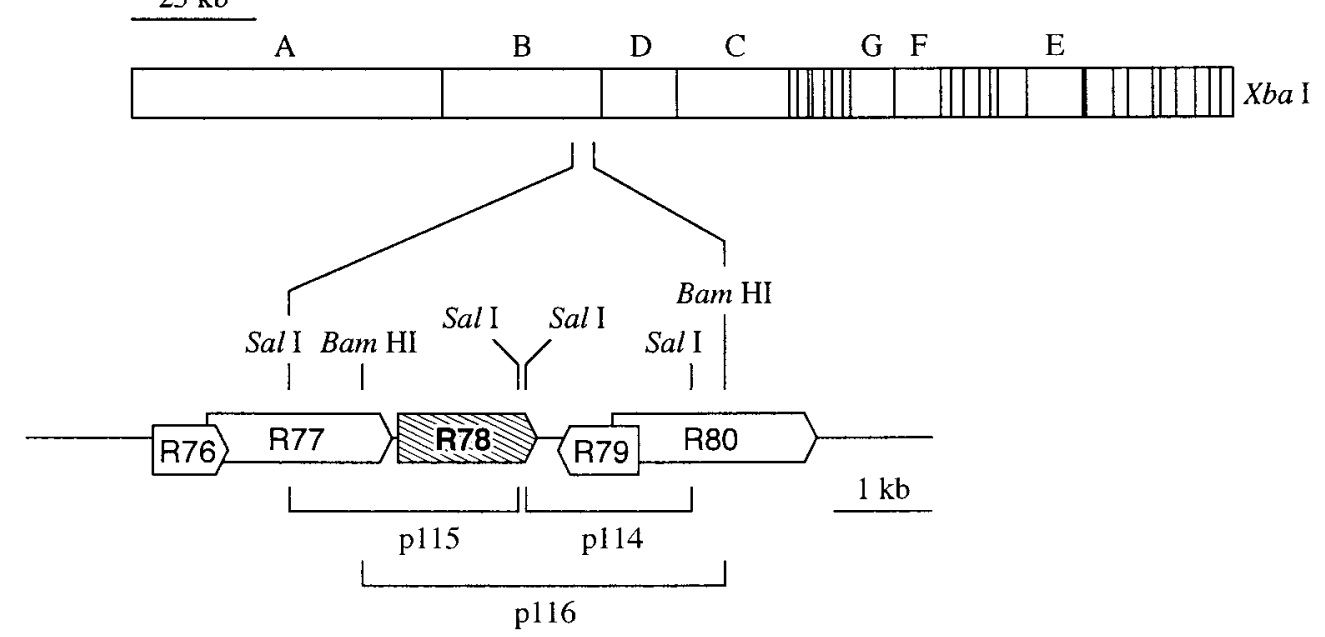

FIG. 1. Restriction map of the RCMV genome and relative position of the R78 gene, which encodes a putative GCR. An enlarged section of the map is shown below. Arrow boxes indicate the size and polarity of conserved RCMV ORFs.

with either RCMVDR78a or RCMV $\mathrm{R} 78 \mathrm{c}$ than in wt RCMVinfected rats. We conclude that the RCMV R78 gene plays a vital role in both RCMV replication in vitro and the pathogenesis of viral infection in vivo.

\section{MATERIALS AND METHODS}

Cells and virus. Primary REF, rat fibroblast cell line Rat2 $\mathrm{TK}^{-}$(ATCC CRL 1764), rat heart endothelium cell line 116 (RHEC), monocyte/macrophage cell line R2 (R2M $\phi$ ), and rat aorta medial smooth muscle cells (RSMC) were cultured as described previously $(18,24,50,60)$. RCMV (Maastricht strain) was propagated in REF (18). Virus titers were determined by a plaque assay using standard procedures (19). RCMV DNA was isolated from culture medium as described by Vink et al. (61).

Identification, cloning, and sequence analysis of the RCMV R78 gene. Cloning of the 30-kb XbaI B fragment of the RCMV genome into vector pSP62-PL has previously been described (45). The $X b a I \mathrm{~B}$ fragment was digested with various restriction endonucleases, and the resulting fragments were cloned into vector pUC119. Both strands of each clone were sequenced by using the Cy5 Autoread sequencing kit (Pharmacia Biotech, Roosendaal, The Netherlands) and ALFexpress automated DNA sequencer (Pharmacia Biotech). Sequence analysis was done with the program PC/Gene (version 2.11; IntelliGenetics). The sequences were checked for the presence of HCMV UL78-homologous regions by alignment with the GenBank nucleic acid database, using the BLASTN search algorithm (39). Thus, a 3.7-kb BamHI fragment was identified, which contains an ORF with considerable similarity to the HCMV UL78 ORF.

RCMV $\Delta R 78$ a recombination plasmid construction. Plasmid p115, which contains a large part of the R78 ORF on a 2.4-kb SalI fragment (Fig. 1), was digested with SalI and subsequently treated with deoxynucleotide triphosphates and DNA polymerase I Klenow fragment (Pharmacia Biotech). Subsequently, the DNA was digested with $B g l I I$, and the resulting 1.4-kb fragment was cloned into BamHI-SmaI-treated vector pUC119, generating plasmid pA. Plasmid p114, which contains the remaining part of the R78 ORF on a 1.7-kb SalI fragment (Fig. 1), was digested with SalI. The 1.7-kb SalI insert from p114 was ligated into the SalI site of pA, generating pB. A 1.5-kb Bam HI-EcoRI fragment from Rc/CMV (Invitrogen, Leek, The Netherlands), containing the neomycin resistance (neo) gene, was treated with Klenow enzyme and ligated into a $\mathrm{Xba \textrm {I } -}$ digested and Klenow enzyme-treated vector pB. This final construct (p147 [see Fig. 4]) was linearized by digestion with Asp 718I and HindIII and used for transfection, in order to generate mutant RCMV $\Delta$ R78a.

RCMV $\Delta R 78$ c recombination plasmid construction. Plasmid p116, which contains the complete R78 ORF on a 3.7-kb Bam HI fragment (Fig. 1), was digested with $A s p 718 \mathrm{I}$ and $N c o$ I. The resulting 2.9 -kb fragment was treated with Klenow enzyme and subsequently circularized with T4 DNA ligase, resulting in plasmid pC. One SalI site was removed from $\mathrm{pC}$ by digestion of the plasmid with $\mathrm{Xba \textrm {I }}$ and HindIII and subsequent treatment with Klenow enzyme. The resulting fragment was circularized, generating plasmid, $\mathrm{pD}$. Plasmid $\mathrm{pD}$ was digested with SalI, treated with Klenow enzyme, and ligated to the blunt-ended DNA fragment containing the Rc/CMV neo gene (see above). The resulting plasmid, p120 (see Fig. 4), was linearized with $A s p 718 \mathrm{I}$ and $X b a \mathrm{I}$ prior to transfection, in order to generate mutant RCMV $\triangle$ R78c.

Generation of RCMV R78 deletion mutants. Approximately $10^{7}$ Rat2 cells were trypsinized and subsequently centrifuged for $5 \mathrm{~min}$ at $500 \times g$. The cells were resuspended in $0.25 \mathrm{ml}$ of culture medium, after which $10 \mu \mathrm{g}$ of linearized plasmid of either p120 or p147 was added. The suspension was transferred to a 0.4-cm electroporation cuvette (Bio-Rad, Veenendaal, The Netherlands) and pulsed at $0.25 \mathrm{kV}$ and $500 \mu \mathrm{F}$ in a Bio-Rad Gene Pulser electroporator. The cells were subsequently seeded in 10-cm-diameter culture dishes. At $6 \mathrm{~h}$ after transfection, the cells were infected with RCMV at a multiplicity of infection (MOI) of 1 . The culture medium was supplemented with $50 \mu \mathrm{g}$ of G418 per ml at $16 \mathrm{~h}$ postinfection (p.i.). Recombinant viruses were plaque purified and cultured on REF monolayers as described earlier (9).

Southern blot hybridization. DNA was isolated from wt RCMV, RCMV $\triangle$ R78a, and RCMV $\triangle$ R78c and then digested with either BamHI, BamHI-BglII, BamHI-EcoRV, BamHI-NcoI, SalI, or SalI-EcoRV. Subsequently, the digested DNA was electrophoresed through a $1 \%$ agarose gel and blotted onto a Hybond $\mathrm{N}^{+}$nylon membrane (Amersham, 's-Hertogenbosch, The Netherlands) as described previously (16). Both a 3.7-kb insert from p116 containing the intact R78 ORF as well as sequences from R77 and R79 (R78 probe [see Fig. $5 \mathrm{~A}]$ ), along with a 1.5-kb Bam HI-EcoRI fragment containing the neo gene (neo probe) from Rc/CMV, were used as probes. Hybridization and detection experiments were performed with digoxigenin DNA labeling and chemiluminescence detection kits (Boehringer Mannheim, Almere, The Netherlands).

Isolation of $\operatorname{poly}(\mathrm{A})^{+}$RNA and Northern blot analysis. RCMV poly $(\mathrm{A})^{+}$ RNA was isolated from REF at 2, 8, and $48 \mathrm{~h}$ p.i. and at immediate-early (IE), early $(\mathrm{E})$, and late $(\mathrm{L})$ times of infection with $\mathrm{RCMV}(\mathrm{MOI}=1)$. To obtain IE mRNA, REF were treated with $100 \mu \mathrm{g}$ of cycloheximide per $\mathrm{ml} 1 \mathrm{~h}$ before, during, and $16 \mathrm{~h}$ after infection. During the 1 -h infection period, the cells were exposed to RCMV. E mRNA was isolated after infection of REF with RCMV and treatment of cells with $100 \mu \mathrm{g}$ of phosphonoacetic acid per $\mathrm{ml}$ from $3 \mathrm{~h}$ p.i. until the cells were harvested at $13 \mathrm{~h}$ p.i. L mRNA was isolated after infection of REF with either RCMV, RCMV $\triangle \mathrm{R} 78 \mathrm{a}$, or RCMV $\triangle \mathrm{R} 78 \mathrm{c}$ and harvesting of cells at $72 \mathrm{~h}$ p.i. To obtain mRNA from mock-infected cells, a procedure similar to that described for the purification of L mRNA was used except that RCMV infection was omitted. Poly(A) ${ }^{+}$RNA was purified with a QuickPrep Micro mRNA purification kit (Pharmacia Biotech). Aliquots $(1 \mu \mathrm{g})$ of poly $(\mathrm{A})^{+}$RNA were electrophoresed through agarose under denaturing conditions as described by Brown and Mackey (17); then the RNA was transferred to positively charged nylon membranes (Boehringer Mannheim) as described previously (17). The 754-bp BamHI-SalI fragment from p115 and the 950-bp BglII-SalI, 206-bp BglIINarI, and 1,088-bp BglII-SalI fragments from p116 (see Fig. 6A) were used to generate probes. These fragments contain R77-, R78-, R79-, and R79/R80specific sequences, respectively. Hybridization and detection experiments were performed with digoxigenin DNA labeling and chemiluminescence detection kits (Boehringer Mannheim).

Replication of $\Delta \mathbf{R 7 8 a}$ and $\Delta \mathbf{R} 78 \mathrm{c}$ in vitro. REF, RHEC, R2M $\phi$, and RSMC were grown either in 96-well plates or on glass slides and infected with either RCMV, RCMV $\triangle \mathrm{R} 78 \mathrm{a}$, or RCMV $\triangle \mathrm{R} 78 \mathrm{c}$ at an MOI of 0.1 or 1 . Culture medium samples (three per virus) were taken at $1,3,5$, and 7 days p.i. and subjected to plaque titer determination. The cells were fixed and stained with monoclonal antibodies (MAbs) against RCMV E proteins (MAb RCMV 8 [20]) as described previously (60). The degree of infection was determined by counting the number of antigen-positive cells relative to the total number of cells in three different wells (four microscopic fields per well at a magnification of $\times 400$ ).

Dissemination of wt RCMV and RCMV $\mathbf{R 7 8 c}$ in vivo. Male specific-pathogen-free Lewis/N RT1 rats (Central Animal Facility, Maastricht University, 
TABLE 1. Similarities of predicted amino acid sequences among R78-like gene products

\begin{tabular}{lcccc}
\hline \multirow{2}{*}{ Gene product } & \multicolumn{4}{c}{ Similarity (\%) $)^{a}$} \\
\cline { 2 - 5 } & RCMV R78 & MCMV M78 & HCMV UL78 & HHV-6 U51 \\
\hline MCMV M78 & 25.0 & & & \\
HCMV UL78 & 20.1 & 20.8 & & \\
HHV-6 U51 & 13.9 & 14.9 & 15.4 & 36.0 \\
HHV-7 U51 & 14.8 & 15.9 & 15.9 & 36.9 \\
\hline
\end{tabular}

${ }^{a}$ Calculated with a pairwise global alignment program (2) that uses an alignment algorithm described by Myers and Miller (46).

Maastricht, The Netherlands), used for all in vivo experiments in this study, were kept under standard conditions (55). Rats were immunocompromised by 5 Gy of total-body Röntgen irradiation 1 day before infection as described by Stals et al. (55), and all virus stocks that were used for inoculation in vivo were derived from tissue culture medium of virus-infected REF. Two groups of rats (10 weeks old; body weight of 250 to $300 \mathrm{~g}$ ) were infected with $5 \times 10^{6}$ PFU of either RCMV or RCMV $\Delta$ R78c. On days 4 and 21 p.i., five rats from each group were sacrificed, and their internal organs were collected. These organs were subjected to both plaque assay and immunohistochemistry (19). Tissue sections (4 $\mu \mathrm{m})$ of the submaxillary salivary gland, spleen, kidney, liver, lung, heart, pancreas, thymus, aorta, and cervical lymph nodes were stained with MAb RCMV 8.

Survival of immunocompromised rats infected with either RCMV, RCMV $\Delta$ R78a, or RCMV $\Delta$ R78c. Four-week-old rats (100 to $120 \mathrm{~g}$ ) were divided into three groups of five rats. Intraperitoneal infection was carried out with $10^{6}$ PFU of either RCMV, RCMV $\triangle \mathrm{R} 78 \mathrm{a}$, or RCMV $\triangle \mathrm{R} 78 \mathrm{c}$. The number of surviving rats was recorded daily until day 28 p.i.

Nucleotide sequence accession number. The nucleotide sequence of the $3.7-\mathrm{kb}$ Bam HI fragment containing the R78 gene (Fig. 1) and the predicted amino acid sequence derived from R78 have been deposited in the GenBank database under accession no. AF077758.

\section{RESULTS}

Identification, cloning, and sequence analysis of the RCMV R78 gene. Previously, it was shown that the majority of RCMV genes are collinear with genes of both HCMV and MCMV (9-11, 61, 62). We hypothesized that the position of a putative RCMV UL78 homolog would be analogous to that of both HCMV UL78 (22) and MCMV M78 (54). Accordingly, we focused on the 33-kb RCMV XbaI B fragment (Fig. 1) (45). This fragment was digested with various restriction endonucleases, subcloned, and sequenced. The GenBank database was subsequently screened for homology with the generated sequence. Thus, we identified (in plasmid p116) a 3.7-kb BamHI fragment showing considerable similarity to a region within the genomes of HCMV as well as MCMV, containing the UL78 and M78 genes, respectively. A 1,422-bp ORF was identified within the Bam HI fragment (Fig. 1), which has the potential to encode a 474-amino-acid polypeptide with a predicted molecular mass of $50 \mathrm{kDa}$. This polypeptide shows 25 and $20 \%$ similarity with the amino acid sequences of M78 (54) and UL78 (22), respectively (Table 1). This low level of similarity is not uncommon to UL78-like sequences, since the amino acid sequences derived from UL78 and M78 share only $21 \%$ similarity (Table 1). In analogy to the nomenclature for the corresponding HCMV and MCMV genes, the 1,422-bp RCMV ORF was termed R78.

To investigate whether the amino acid sequence of the R78derived polypeptide ( $\mathrm{pR} 78$ ) possesses features that are characteristic of GCRs, the pR78 sequence was analyzed with computer program TMpred (ISREC Bioinformatics Group, Epalinges, Switzerland [58]). This program utilizes a database of existing transmembrane domains to predict potential transmembrane domains of an uncharacterized sequence. Computation revealed an extracellular $\mathrm{N}$ terminus and eight transmembrane domains, each of which might be folded as an $\alpha$ helix. Seven of these domains are collinear with the predicted transmembrane domains of the gene products of MCMV M78 and HCMV UL78 (Fig. 2). In addition, several amino acid residues that are conserved among most GCRs were identified (reviewed by Probst et al. [53]): two conserved cysteine residues at positions 94 and 190, which may form a disulfide bridge, and a conserved aspartic acid-arginine-leucine (DRL) motif (positions 118 to 120 ) that might be involved in G protein coupling (Fig. 2). These residues are also present within analogous regions of the UL78 and M78 gene products and the HHV-6 and -7 U51 gene products (Fig. 2). Another interesting feature is the presence of a putative tyrosine kinase phosphorylation site (phosphorylation consensus $[\mathrm{R} / \mathrm{K}] \mathrm{X}_{2 / 3}[\mathrm{D} / \mathrm{E}] \mathrm{X}_{2 / 3} \mathrm{Y}$, at positions 392 to 400 ) (Fig. 2). These putative tyrosine phosphorylation sites are found in the predicted amino acid sequences of RCMV R78, MCMV M78, and HCMV UL78 but not in analogous regions of the predicted U51 amino acid sequence of either HHV-6 or HHV-7 (Fig. 2).

In order to classify the GCRs encoded by the R78-like genes, the predicted amino acid sequences of R78, M78, UL78, and HHV-6 and -7 U51 were screened against a nonredundant protein sequence data set (a combination of all nonredundant GenBank complete protein coding gene translations plus sequences from the Protein Data Bank, SwissProt, and Protein Information Resource databases [39]). This analysis demonstrated a clear relationship between pR78-like peptides and other GCRs; the predicted amino acid sequence of the UL78 gene was similar to sequences of GCRs such as a thrombin receptor (32) and opioid receptor (66), while the M78 gene product shows similarity with a lysophosphatidic acid receptor (3) and a somatostatin-like receptor (64). Surprisingly, the sequence of the $\mathrm{C}$-terminal part of the R78 gene product was found to be similar to collagen-like sequences (in particular sequences such as human collagen (51) and spider silk protein (65). Although previously examined virus-encoded GCRs were shown to be related to chemokine receptors $(1,4,9,21,26,30$, $38,42,44,47,57,63)$, none of the pR78-like GCRs showed a collective similarity with GCRs of any particular class. Most notably, the N-terminal part of the R78-like gene products lack the signals for $\mathrm{N}$-linked glycosylation, which are present in the $\mathrm{N}$-terminal sequences of all other known virus-encoded GCRs, making this a unique set of receptors among virus-encoded GCRs.

R78 transcription. Although the ORFs of R78-like betaherpesvirus genes are poorly conserved, they are all preceded by a remarkable double TATA signal motif. Moreover, the start codons of R78, M78, and UL78 conform to the Kozak consensus (41). The positions and sequences of these motifs are summarized in Table 2 . We set out to identify transcripts derived from the RCMV R78 gene by Northern blot analysis. As shown in Fig. 3, R78-specific hybridization signals were detected in phosphonoacetic acid-treated (lane 3) and untreated (lane 4) cells but not in cycloheximide-treated (lane 2) or mock-infected (lane 1) cells. In untreated, RCMV-infected REF, R78-specific signals were detected at 8 and $48 \mathrm{~h}$ p.i. (lanes 7 and 8, respectively) but not at earlier time points (lane 5 and 6, respectively). These results classify R78 as an E gene that is also transcribed during the $\mathrm{L}$ phase of infection in vitro.

An R78-specific transcript with a length of approximately 1.8 $\mathrm{kb}$ was detected during both the $\mathrm{E}$ and $\mathrm{L}$ phases (Fig. 3, lanes $3,4,7$, and 8 ). Since the R78 ORF was found to comprise 1,422 $\mathrm{bp}$, and a putative polyadenylation signal (AATAAA) is located 94 bp downstream of the R78 ORF, we postulate that the $1.8-\mathrm{kb}$ transcript corresponds to an mRNA that exclusively contains the R78 ORF. Two other R78-specific transcripts (3.7 and $5.7 \mathrm{~kb}$, respectively) were detected during the $\mathrm{L}$ phase 


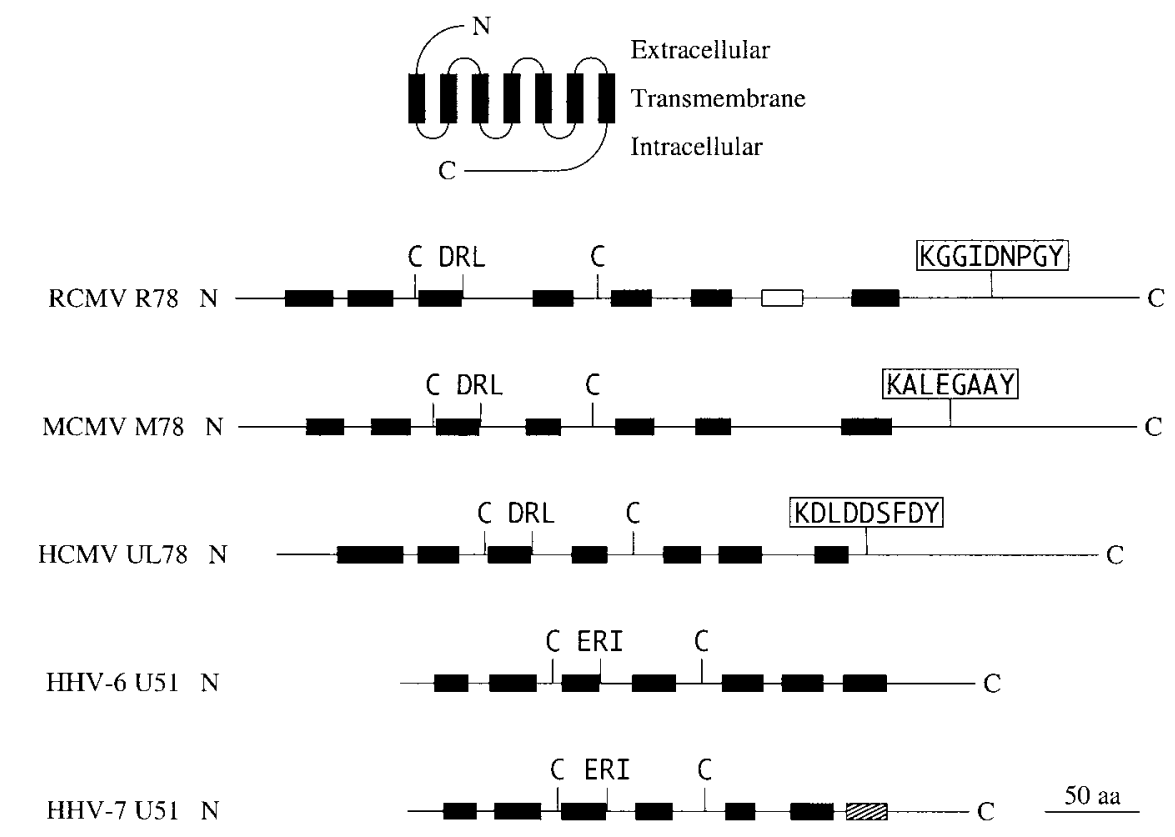

FIG. 2. Schematic representation of the gene products of RCMV R78, MCMV M78, HCMV UL78, and HHV-6 and -7 U51. The top drawing shows the two-dimensional orientation of GCRs (not to scale with diagrams of the other GCRs). Horizontal lines represent the one-dimensional structure of the R78-like gene products; designations of the genes that encode these receptors are shown at the left. Black boxes represent putative transmembrane $\alpha$ helices; the white box indicates an additional unique hydrophobic $\alpha$-helix domain predicted by the computer program TMpred (58); the hatched box indicates a hydrophobic stretch of amino acid residues collinear with predicted transmembrane domains of the other GCRs, although not predicted by TMpred. Conserved cysteine residues are indicated by C's. The $(\mathrm{D} / \mathrm{E}) \mathrm{R}(\mathrm{I} / \mathrm{L})$ motifs indicate positions of the conserved putative $\mathrm{G}$ protein-coupling domains. The sequences enclosed in white boxes indicate positions of putative tyrosine kinase phosphorylation sites that are conserved among CMV genes relative to R78.

(lane 4) and at $48 \mathrm{~h}$ p.i. (lane 8). At $8 \mathrm{~h}$ p.i., we detected a $3.9-\mathrm{kb}$ transcript (lane 7 ) but not the $3.7-\mathrm{kb}$ transcript. It is possible that early after infection the combined transcription of R77 and R78 is initiated at a location $0.2 \mathrm{~kb}$ upstream of the transcription start site of the $3.7-\mathrm{kb}$ transcript. Alternatively, since we did not use strand-specific probes, the 3.9-kb transcript could have derived from the opposite strand of the R77/R78 locus. However, this was not investigated further. The 3.9- and 3.7-kb transcripts may contain the R78 ORF as well as one or more neighboring ORFs. This hypothesis is supported by the notion that the gene upstream of R78 (R77; see below) lacks a polyadenylation site at its $3^{\prime}$ end. Additional Northern blot hybridization data (shown below) support the hypothesis of cotranscription of R77, R78, and other RCMV genes.

Generation of RCMV strains with a deletion of the R78 gene. To investigate the role of R78 in the pathogenesis of RCMV disease, we constructed a mutant RCMV strain (RCMV $\Delta$ R78a) in which a 1,030-bp BglII-SalI fragment from the R78 gene was deleted and replaced with a $1.5-\mathrm{kb}$ neo expression cassette (Fig. 4). Another RCMV mutant strain (RCMV $\Delta$ R78c) was constructed such that an 80-bp SalI fragment was replaced by the neo cassette (Fig. 4). Consequently, the part of R78 that encodes the putative intracellular $\mathrm{C}$ terminus was deleted and replaced by an irrelevant sequence of similar length, while the part that encodes the $\mathrm{N}$ terminus (including the seven predicted transmembrane helices) was preserved (Fig. 4). The deletion/insertion mutations were first introduced into plasmids containing the R78 gene (Fig. 4). The R78 gene within the RCMV genome was subsequently replaced by either of the mutated R78 genes via homologous recombination, after transfection of fibroblasts with the recombination plasmids and infection with RCMV. Selection for recombinant strains was established by supplementing the growth medium with G418. After plaque purification of the virus, the purity and integrity of the recombinant strains were checked by Southern blot analysis. Virion DNA from RCMV, $\mathrm{RCMV} \Delta \mathrm{R} 78 \mathrm{a}$, and RCMV $\mathrm{R} 78 \mathrm{c}$ was purified and digested with BamHI-NcoI (Fig. 5). We also digested purified virion DNA with either BamHI, BamHI-BglII, BamHI-Eco RV, NcoI,

TABLE 2. Transcription initiation and translation signals of R78-like genes are conserved ${ }^{a}$

\begin{tabular}{|c|c|c|c|c|c|c|c|}
\hline \multirow{2}{*}{ Virus } & \multirow{2}{*}{ Gene } & \multicolumn{2}{|c|}{ TATA box 1} & \multicolumn{2}{|c|}{ TATA box 2} & \multicolumn{2}{|c|}{ Kozak } \\
\hline & & Sequence & Position & Sequence & Position & Sequence & Position \\
\hline RCMV & $\mathrm{R} 78$ & TATTTG & -108 to -103 & TATAAG & -62 to -57 & GCCACGATGG & \\
\hline MCMV & M78 & TATTTT & -148 to -143 & TATAAG & -104 to -99 & GTCGCCATGC & \\
\hline HCMV & UL78 & TATTTA & -149 to -144 & TAATTT & -91 to -86 & TCCATCATGT & 37 to $46^{b}$ \\
\hline HHV-6 & U51 & TATTTT & -140 to -135 & TATATA & -103 to -97 & & \\
\hline HHV-7 & U51 & TATTTT & -146 to -141 & TATAAA & -69 to -64 & & \\
\hline
\end{tabular}

${ }^{a}$ Sequences are described in references $22,33,49$, and 54. All positions are relative to the first nucleotide of the corresponding ORF.

${ }^{b}$ Contains an in-frame ATG sequence and is present downstream of the previously predicted start codon of UL78. 


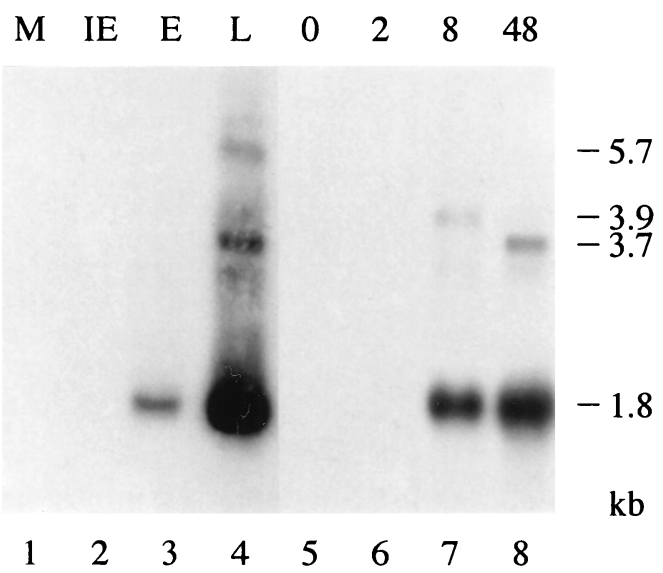

FIG. 3. The RCMV R78 gene is transcribed at both $\mathrm{E}$ and $\mathrm{L}$ times of infection in REF. Lanes 1 and 5 of the autoradiograph of a Northern blot hybridized with an R78-specific probe represent mRNA from mock-infected (M) cells. Lanes 2 to 4 represent the IE, E, and L phases of infection, respectively; lanes 6 to 8 represent transcripts from $\mathrm{REF}$ at 2,8 , and $48 \mathrm{~h}$ p.i., respectively. The estimated lengths of the different transcripts are indicated at the right in kilobases.

SalI, or SalI-EcoRV (data not shown). After agarose gel electrophoresis and transfer of the DNA to a filter, hybridization was done with either an R78-specific probe or a neo-specific probe. As shown in Fig. 5, the observed hybridization signals correspond exactly to the predicted restriction fragments. In addition, contaminating wt virus fragments were not detected in the RCMV R78a and RCMV R 78c lanes (Fig. 5). These findings indicated that both recombinant strains are pure and contain the appropriate mutations.

RCMV $\Delta$ R78c transcripts. The deletion of the R78 ORF might invoke unforeseen events such as disruption of unknown promoter/enhancer regions of the neighboring gene R77, R79, or R80. To investigate the effect of modification of the R78 genes on transcription of these neighboring genes, a Northern blot hybridization experiment was performed with poly $(\mathrm{A})^{+}$ RNA from REF infected with one of the two recombinant viruses (RCMVDR78c) and wt RCMV-infected REF. The genes upstream and downstream of the R78 gene were found to have considerable sequence similarity to the MCMV M77, M79, and M80 genes (54), respectively (data not shown). These RCMV genes are therefore referred to as R77, R79, and R80, respectively. Probes were generated from R77-, R78-, R79-, R79/R80-, and neo-specific DNA fragments (Fig. 6A and B) and hybridized with poly $(\mathrm{A})^{+}$RNA extracted from either mock-, RCMV-, or RCMV $\Delta$ R78c-infected fibroblasts at $48 \mathrm{~h}$ p.i. (Fig. 6C).

In agreement with a previous Northern blot hybridization experiment (Fig. 3), the R78-specific probe hybridized to three distinct RCMV transcripts of 1.8, 3.7, and albeit weakly, $5.7 \mathrm{~kb}$, respectively (Fig. 6C, lane 5). Our hypothesis that the larger two of these R78-specific transcripts also contained the R77 ORF was verified by hybridization with an R77-specific probe, which led to the detection of similar 3.7- and 5.7-kb transcripts (lane 2). In poly (A) ${ }^{+}$RNA from RCMV R78c-infected REF, the R77-specific probe and the R78-specific probe hybridized to similar transcripts. Interestingly, these transcripts are approximately $1 \mathrm{~kb}$ longer than their counterparts from wt RCMV-infected REF (lanes 3 and 6). These transcripts also hybridized to a neo-specific probe (lane 15), indicating that the 2.8-kb transcript (lanes 6 and 15) contains the modified R78 ORF as well as neo sequences, and both the $4.7-\mathrm{kb}$ transcript (lanes 3, 6, and 15) and the 6.7-kb transcript (lanes 3, 6, and 15) encompass R77, the modified R78 ORF, as well as neo sequences (Fig. 6B). Additionally, the neo probe hybridized to a unique 1.2-kb transcript (lane 15). A similar neo-specific transcript was previously found to be expressed by an RCMV strain (RCMV $\Delta$ R33) of which the R33 gene was disrupted by the neo gene (9).

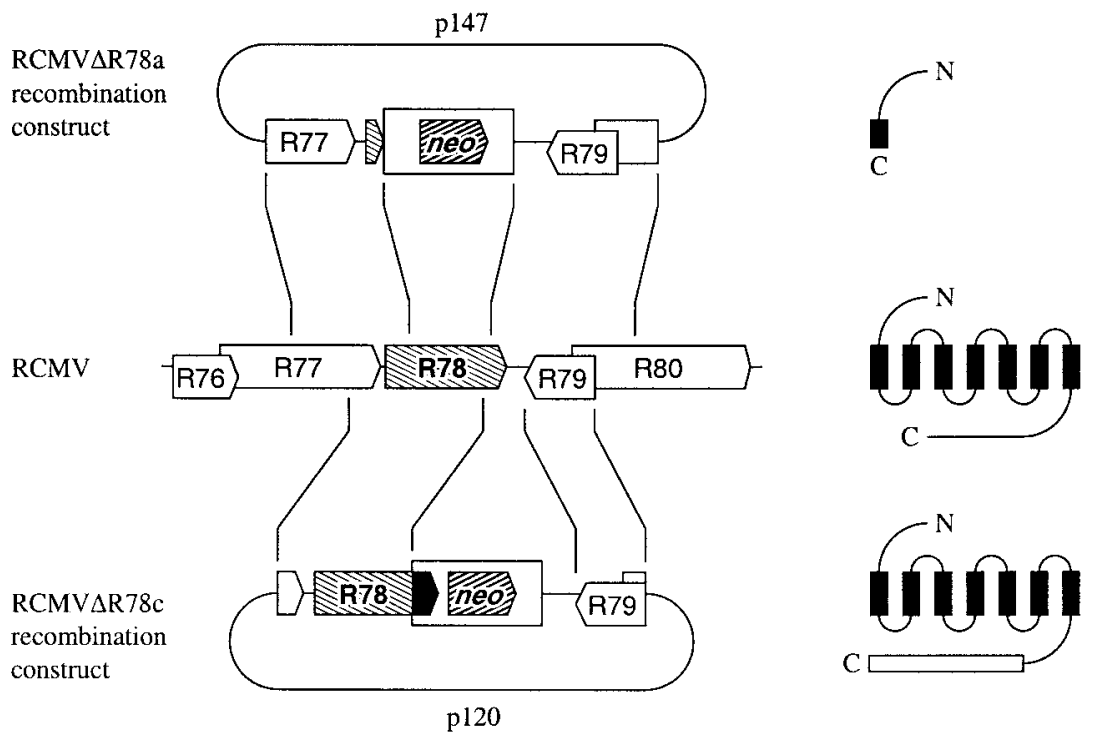

FIG. 4. Construction of RCMV strains in which the R78 gene is disrupted. The RCMV genome, of which a segment representing the R78 region is shown in the middle, was modified by homologous recombination with different recombination plasmids (p147 [top] or p120 [bottom]), resulting in RCMV $\Delta \mathrm{R} 78 \mathrm{a}$ or RCMV $\mathrm{R} 78 \mathrm{c}$, respectively. Approximately $85 \%$ of the R78 ORF has been deleted in the RCMVDR78a genome (resulting in a gene encoding only the N-terminal part including half of the first predicted transmembrane domain, shown at the top right). In mutant RCMV $\Delta \mathrm{R} 78 \mathrm{c}$, the part of the R78 that encodes the putative intracellular C terminus has been replaced by a sequence encoding a stretch of 97 amino acids of irrelevant sequence (bottom right, indicated as a black arrow box). ORFs are shown as arrow boxes. Wild-type and mutated R78 ORFs are indicated with descending hatches. The neo genes that were inserted in the recombination plasmids are indicated with ascending hatches. 
A

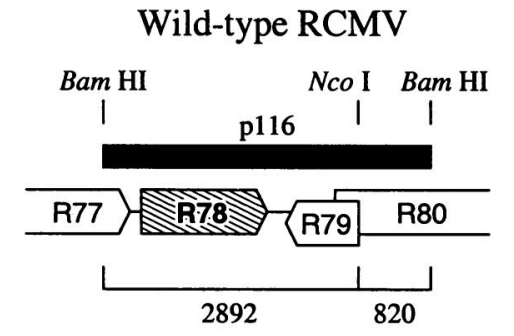

Wild-type RCMV

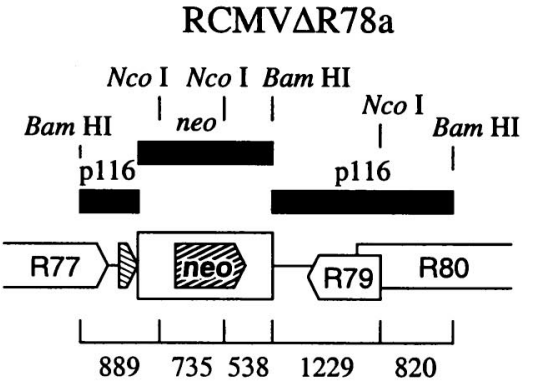

\section{RCMV $\Delta \mathrm{R} 78 \mathrm{c}$}

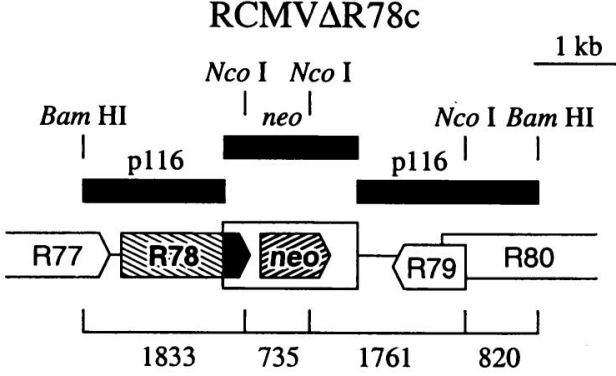

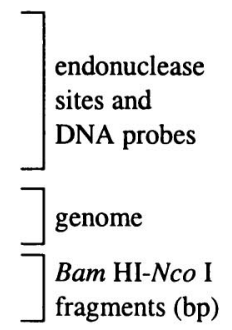

B
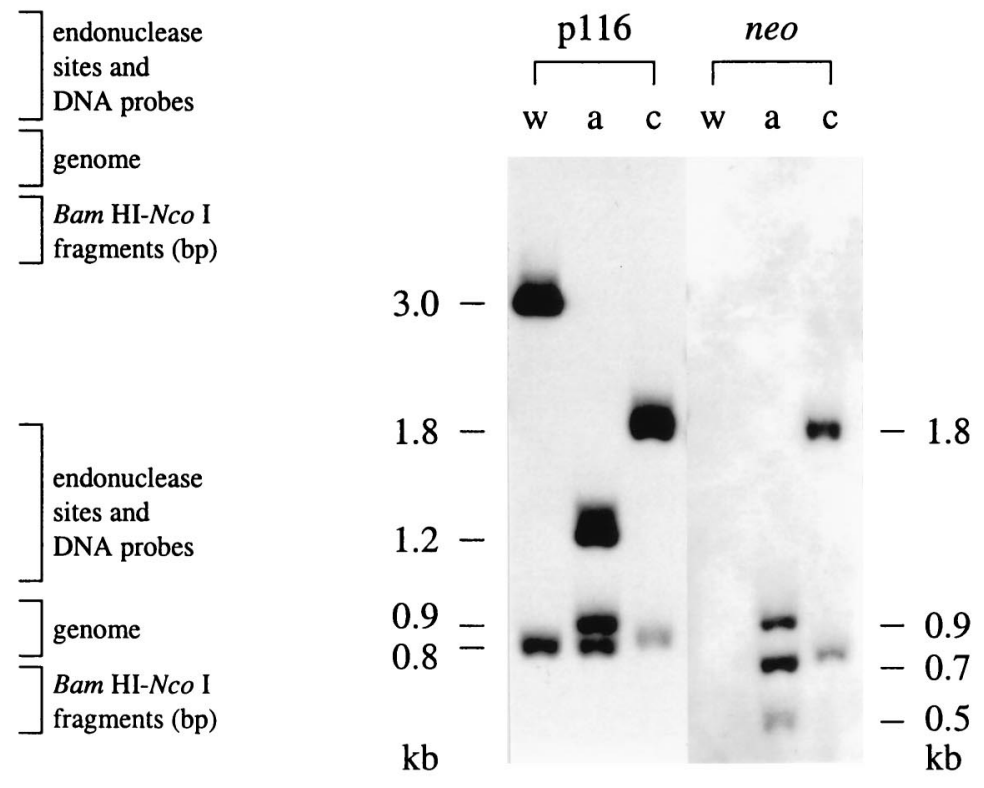

$\begin{array}{llllll}1 & 2 & 3 & 4 & 5 & 6\end{array}$

FIG. 5. Southern blot analysis of recombinant viruses RCMV $\Delta$ R78a and RCMV R78c. (A) DNA from RCMV, RCMV $\Delta$ R78a, and RCMV $\Delta$ R78c was digested with Bam HI and NcoI, electrophoresed, blotted, and hybridized with either a probe derived from the p116 insert or a neo probe (both indicated with black boxes). ORFs are shown as arrow boxes. Wild-type and mutated R78 ORFs are indicated by descending hatches. The neo genes that were inserted in the recombination plasmids are indicated by ascending hatches. (B) Autoluminograph of a Southern blot containing wt (w) DNA, RCMVDR78a (a) DNA, and RCMVAR78c (c) DNA. The estimated lengths of Bam HI-NcoI-digested DNA fragments are indicated at the sides in kilobases.

R79-specific transcripts were detected in neither wt RCMVnor RCMV $\Delta$ R78c-infected REF (Fig. 6C, lanes 8 and 9). This might be a consequence of either a low level of R79 transcription or low efficiency of labeling of the R79-specific probe that was used for hybridization. Thus, a larger probe specific for both R79 and R80 was derived from the 1088-bp BglII-SalI fragment from plasmid p116 (Fig. 6A and B). With this probe, transcripts of similar lengths $(2.4 \mathrm{~kb})$ were detected in either RCMV- or RCMV $\Delta$ R78c-infected REF (Fig. 6C, lanes 11 and 12). Since the lengths of these transcripts correspond to the size of the R80 ORF (2,457 bp [13]), we hypothesize that they contain R80 mRNA rather than R79 mRNA (Fig. 6A and B). Although we cannot formally exclude the possibility that disruption of the R78 ORF affects transcription of the R79 gene, we hypothesize that transcription of R79 does not differ between RCMV and RCMV $\triangle$ R78c. This hypothesis is based on the following two observations. First, the putative promoter of R79 is likely to be situated upstream of the R79 ORF, within the R80 ORF distant from the disrupted R78 site in RCMV $\Delta$ R78c. In addition, a potential polyadenylation site downstream of the R79 ORF and neighboring the R78 ORF (complementary to nucleo- tides 1858 to 1863 of GenBank accession no. AF077758) is preserved in both RCMV $\Delta$ R78c and RCMV $\Delta$ R78a.

The $\mathbf{R 7 8}$ gene is important for efficient virus replication in various cell types in vitro. The replication characteristics of RCMV, RCMV R 78a, and RCMV $\Delta \mathrm{R} 78 \mathrm{c}$ were assessed in four different cell types: REF RHEC, RSMC, and R2M $\phi$. Cells were infected with either RCMV, RCMV $\triangle$ R78a, or $\mathrm{RCMV} \Delta \mathrm{R} 78 \mathrm{c}$, and the proportion of infected cells relative to the total population of cells was determined at various time points. Additionally, the amount of excreted infectious virus was determined for each cell type. As shown in Fig. 7, the infected cell ratios did not differ significantly among REF and RSMC infected with either wt RCMV or each of the recombinant viruses during the observed time course. Also, infected cell ratios as well as virus titers in the culture medium of RHEC and R2M $\phi$ infected with either wt or recombinant virus did not differ significantly (data not shown). However, clear differences were observed in virus titers in the culture medium of virus-infected REF and RSMC. In particular, at days 5 and 7 p.i., virus titers were 10 - to 100 -fold lower in the culture medium of both RCMV $\Delta$ R78a- and RCMV $\Delta$ R78c-infected 

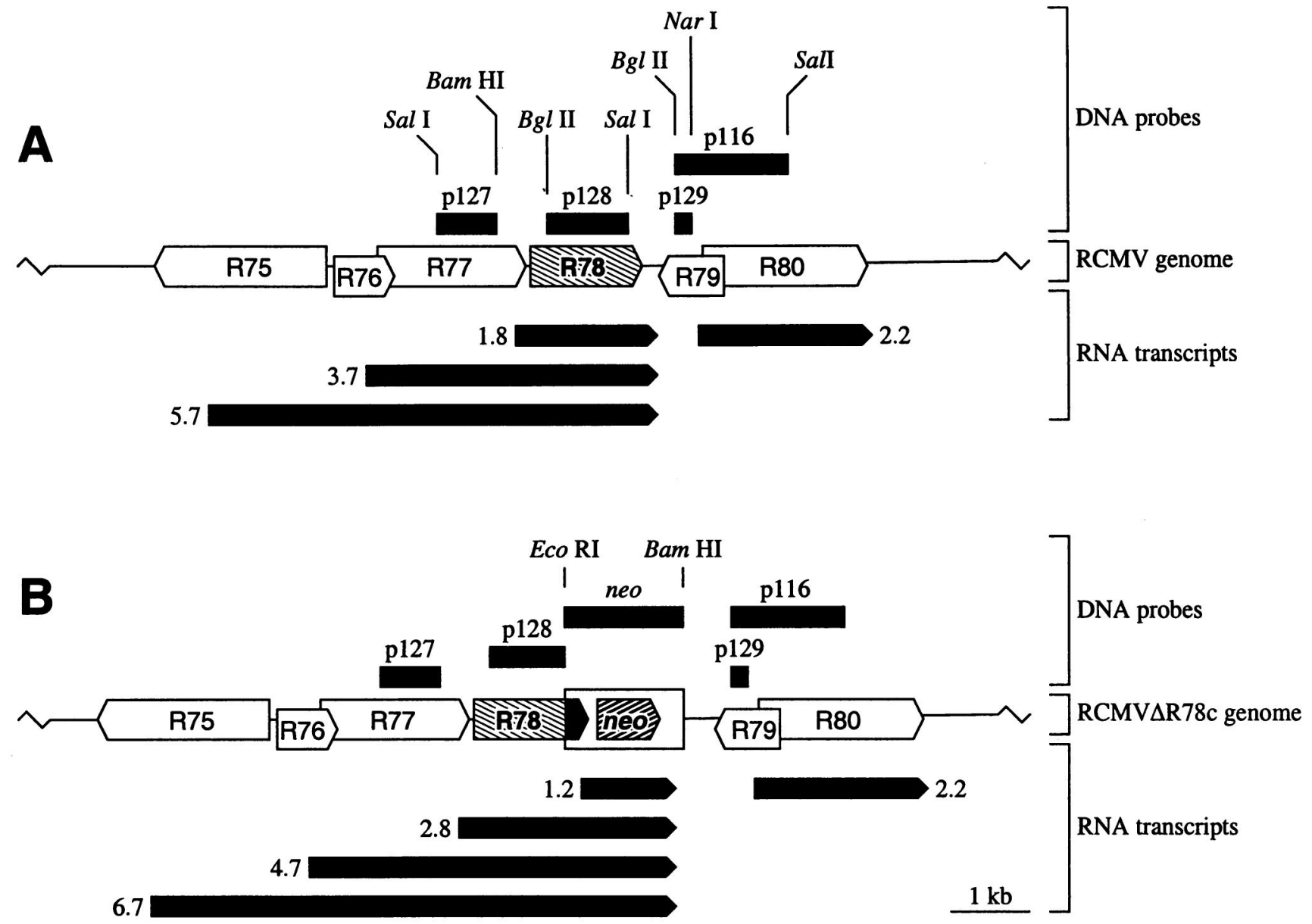

C

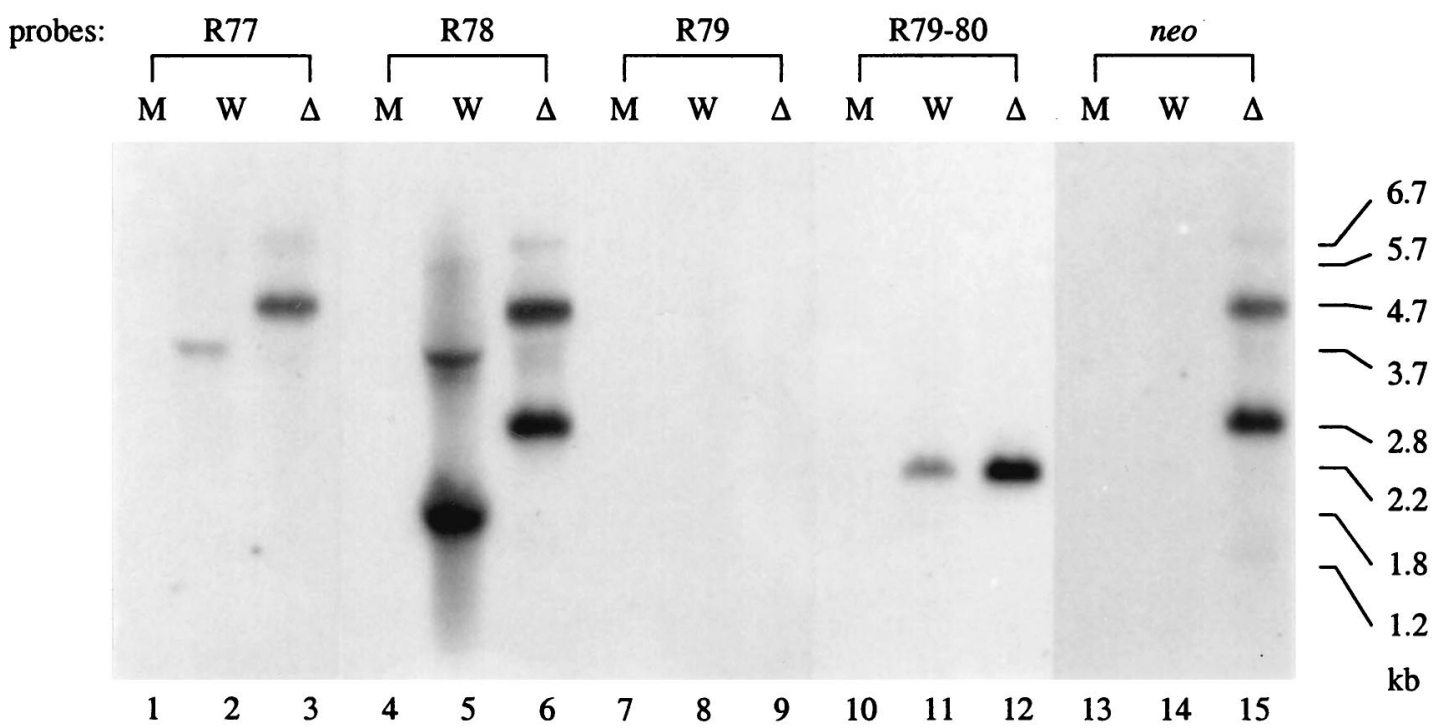

FIG. 6. Transcription of R78 and neighboring genes. The wt RCMV (A) and RCMV $\mathrm{R} 78 \mathrm{c}$ (B) genomes are represented by lines. ORFs are indicated by white, hatched, and black arrow boxes, probes are indicated by black boxes, and transcripts are indicated by black arrow boxes below the genomes. Lengths are shown at the sides in kilobases. (C) Autoluminographs from Northern blots that contain poly(A) ${ }^{+}$RNA from virus-infected REF. The transcript lengths that correspond to the detected hybridization signals are indicated in kilobases. M, mock infected; W, wt RCMV infected; $\Delta$, RCMV $\Delta$ R78c infected. 

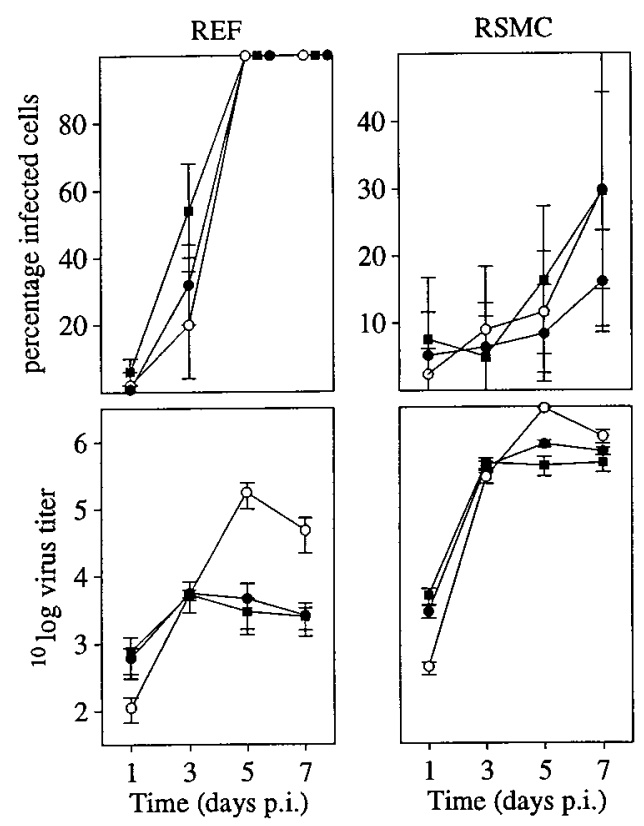

FIG. 7. RCMV is attenuated upon deletion of the R78 gene. REF were infected at an MOI of 0.01 with either wt RCMV (O), RCMV R78a ( $\boldsymbol{\square})$, or RCMV $\Delta$ R78c $(\bullet)$. RSMC were infected with wt and mutant virus at an MOI of 1 (relative to REF infection). The upper graphs show the infected cell/total cell ratios at various time points p.i.; the lower graphs show virus titers determined in culture medium up to 7 days p.i. Standard deviations are indicated by vertical bars.

REF than in the culture medium of wt RCMV-infected REF (Fig. 7). Additionally, at day 5 p.i., virus titers were 10 -fold lower in the culture medium of recombinant virus-infected RSMC than in the medium of wt virus-infected RSMC (Fig. 7). Taken together, these data suggest that (i) R78-deleted viruses enter cells and spread throughout the monolayers of cells at similar rates as wt virus and (ii) in REF and RSMC, the production of recombinant virus is less efficient than the production of wt virus.

RCMV $\Delta$ R78a and RCMV $\Delta$ R78c induce syncytium formation in REF. In addition to the differences in virus replication between wt and mutant viruses, the morphology of REF infected with either RCMV $\Delta$ R78a or RCMV $\Delta \mathrm{R} 78 \mathrm{c}$ clearly contrasted with that of wt virus-infected REF. Within the monolayers of mutant RCMV-infected REF (Fig. 8C and D) but not in those of infected RSMC, RHEC or R2M $\phi$, we observed syncytium-like cellular cultures that were larger than those typically seen in wt RCMV-infected REF monolayers (Fig. $8 \mathrm{~B})$. These structures appear 3 to 4 days p.i. To investigate the nature of these structures more closely, they were subjected to immunofluorescence staining and confocal laser scan microscopy. To this purpose, virus-infected REF were stained with
MAb RCMV 8, which detects E-phase-expressed antigens in the nuclei (20). Additionally, these cells were counterstained with phalloidin, which binds to cytoskeletal F-actin fibers localized in the cytoplasm. MAb RCMV 8 and phalloidin were labeled with fluorescent markers fluorescein isothiocyanate and rhodamine, respectively. Surprisingly, the large structures that were seen in either RCMV $\Delta$ R78a- or RCMV $\Delta$ R78c-infected REF appeared to consist of a single cytoplasmic entity encapsulating 2 to 20 distinct nuclei. A typical example of such a syncytium-like structure is shown in Fig. 8E. The significance of these polykaryotic cells, or syncytia, and their relation to the function of the R78 gene is discussed below.

$\mathrm{R78}$ has a critical function in the pathogenesis of RCMV infection in vivo. The role of $\mathrm{R} 78$ in the pathogenesis of RCMV disease was investigated by infection of rats with either wt or mutant virus. To compare virus dissemination in wt virus-infected and mutant virus-infected rats, two groups of immunocompromised rats were infected with $5 \times 10^{6} \mathrm{PFU}$ of either RCMV or RCMV $\triangle$ R78c. At days 4 and 21 p.i., the presence of virus in internal organs (aorta, heart, kidney, liver, lung, lymph nodes, pancreas, salivary glands, spleen, and thymus) of the infected rats was determined. At day 4 p.i., virus could be detected in $18 \%$ of the aforementioned organs in $\mathrm{wt}$ $\mathrm{RCMV}$-infected rats and in $9 \%$ of the organs of RCMV $\Delta \mathrm{R} 78 \mathrm{c}-$ infected rats, as determined by either plaque assay or immunohistochemistry. At this time point, the highest virus titers were found in the spleens of wt virus- or mutant virus-infected rats. In contrast to the marked differences in replication efficiency between wt and deletion mutant virus in vitro, the differences in the amount of virus recovered from either spleen (Table 3) or other organs (not shown) of infected rats were less dramatic. Neither wt nor mutant virus could be detected in the liver, pancreas, and salivary glands at day 4 p.i. At day 21 p.i., virus could be recovered from salivary glands of both wt RCMV- and RCMV $\Delta$ R78c-infected rats but not from any of the other organs analyzed. Surprisingly, virus titers in salivary glands did not differ significantly between RCMV- and RCMV $\triangle$ R78cinfected rats (Table 3).

In a separate in vivo experiment, the virulence of wt and mutant viruses was determined by infecting rats with potentially lethal doses of virus. To this purpose, three groups of 4-week-old immunosuppressed rats were infected with $10^{6}$ PFU of either RCMV, RCMV $\Delta$ R78a, or RCMV R78c. Surprisingly, we found that mortality was dramatically lower in RCMV $\Delta$ R78a- and RCMV R 78c-infected rats than in RCMVinfected rats (Fig. 9). This result indicates that R78 plays an important role in the pathogenesis of RCMV infection.

\section{DISCUSSION}

Herpesviruses are known for the large size and complexity of their genomes, which encompass a vast number of genes, many of which are homologous to genes of the host organism. Betaand gammaherpesvirus genomes contain genes homologous to

TABLE 3. Virus titers and immunohistochemical detection of RCMV and RCMV $\Delta$ R78c in salivary glands and spleen tissue

\begin{tabular}{|c|c|c|c|c|c|c|c|c|}
\hline \multirow{3}{*}{ Virus } & \multicolumn{4}{|c|}{ Salivary gland } & \multicolumn{4}{|c|}{ Spleen } \\
\hline & \multicolumn{2}{|c|}{ Day 4 p.i. } & \multicolumn{2}{|l|}{ Day 28 p.i. } & \multicolumn{2}{|l|}{ Day 4 p.i. } & \multicolumn{2}{|c|}{ Day 28 p.i. } \\
\hline & $\begin{array}{c}\text { Titer } \\
\left(\log _{10} \mathrm{PFU} / \mathrm{ml}\right)\end{array}$ & IPOX $^{a}$ & $\begin{array}{c}\text { Titer }^{a} \\
\text { mean } \log _{10} \mathrm{PFU} / \mathrm{ml} \pm \mathrm{SD}\end{array}$ & IPOX & $\begin{array}{c}\text { Titer }^{a} \\
\text { mean } \log _{10} \mathrm{PFU} / \mathrm{ml} \pm \mathrm{SD}\end{array}$ & IPOX & $\begin{array}{c}\text { Titer } \\
\left(\log _{10} \mathrm{PFU} / \mathrm{ml}\right)\end{array}$ & IPOX \\
\hline RCMV & $<1$ & 0 & $8.6 \pm 0.3$ & 5 & $2.7 \pm 0.3$ & 2 & $<1$ & 0 \\
\hline $\mathrm{RCMV} \Delta \mathrm{R} 78 \mathrm{c}$ & $<1$ & 0 & $8.2 \pm 0.2$ & 5 & $1.3 \pm 0.7$ & 0 & $<1$ & 0 \\
\hline
\end{tabular}

${ }^{a}$ Immune peroxidase assay (IPOX) data are presented as the number of rats of which the organ tissue was found RCMV positive of five rats tested. 

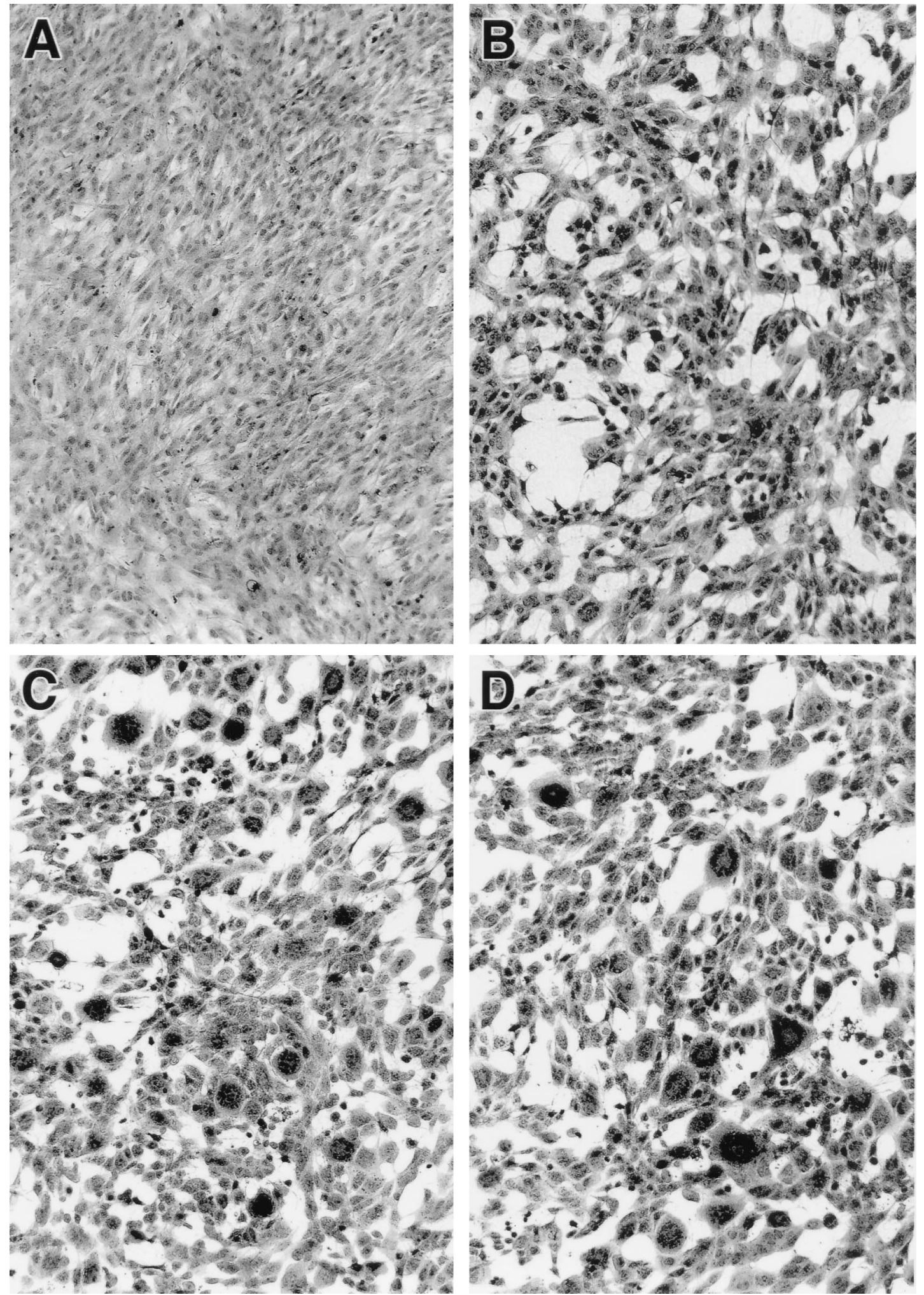

FIG. 8. RCMV R78 deletion mutants induce syncytium formation in vitro. Immunofluorescence micrographs (magnification of $\times 400)$ show uninfected REF (A) nd REF infected with either wt RCMV (B), RCMV $\triangle$ R78a (C), or RCMVAR78c (D). (E) Confocal laser scan micrograph taken from a syncytium structure in a monolayer of RCMV $\mathrm{R} 78 \mathrm{c}$-infected REF. The scale bar indicates $20 \mu \mathrm{m}$. The left-hand frame shows intracellular F-actin fibers that were stained with phalloidinrhodamin (Eugene, Leiden, The Netherlands); the right-hand frame, of the same microscopic view, shows the nucleic distribution of RCMV E antigens detected by MAb RCMV 8 plus anti-mouse-fluorescein isothiocyanate. 

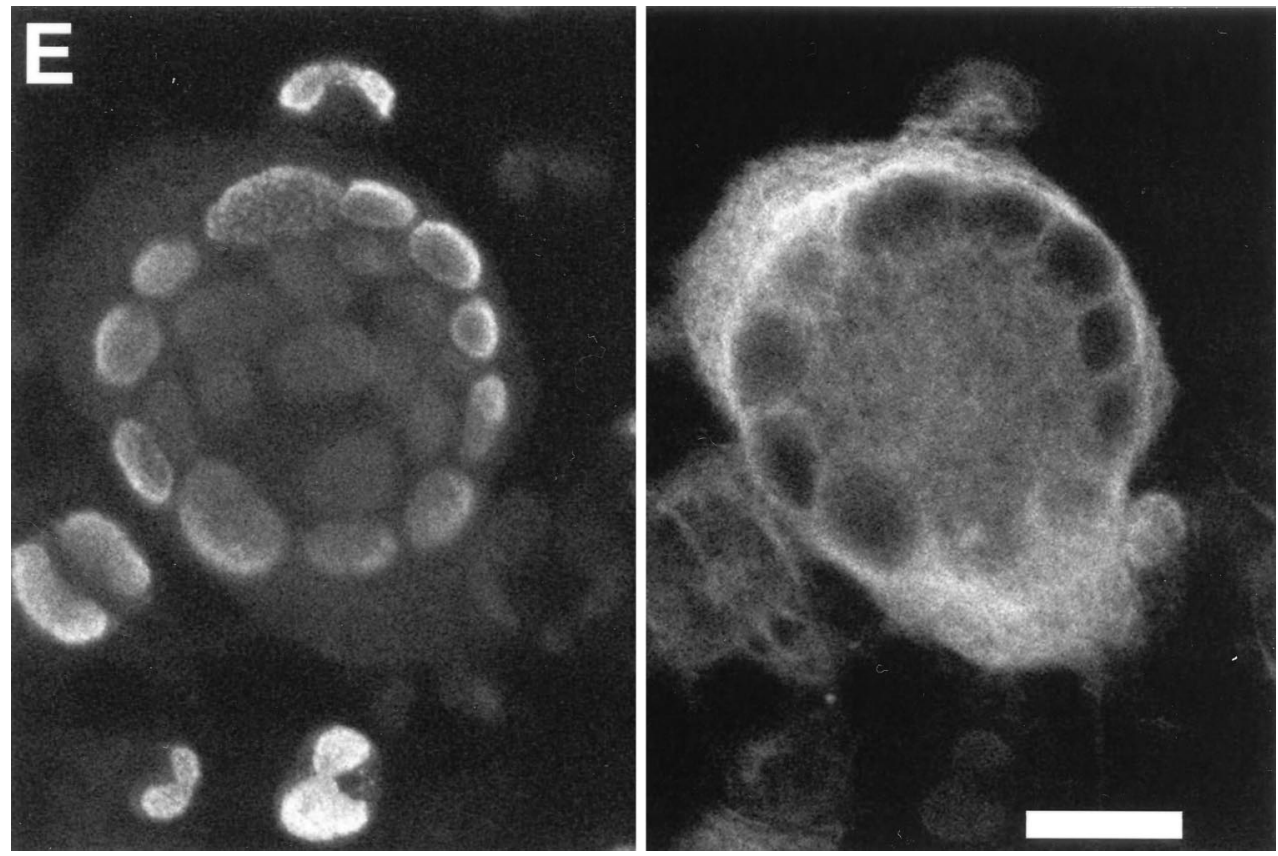

FIG. 8-Continued

GCR genes of the host. Eighteen beta- and gammaherpesvirus-encoded GCR genes have been recognized to date $(4,9$, 21-23, 25, 33, 44, 49, 48, 54, 57, 63). These genes can be arranged into four groups based on sequence homology, genome location, and function of the respective gene product. One group (the US28 family) consists of two GCR genes: US27 and US28 (23). Both are exclusively present within an unconserved region of the HCMV genome (22). These GCRs are highly similar to mammalian chemokine receptors $(15,30)$. Although little is known about the function of the GCR encoded by US27, the HCMV US28-encoded GCR is a wellstudied example of a virus-encoded GCR with an immunomodulatory function. This receptor was shown to bind $\beta$ chemokines MIP1 $\alpha$, MIP1 $\beta$, RANTES, MCP-1, and MCP-3 $(14,31,47)$. Additionally, Bodaghi et al. reported that the US28 gene product modifies the chemokine environment of HCMV-infected cells through sequestering of $\beta$ chemokines by continuous internalization (15). A second group (the UL33 family) contains five GCR genes: HCMV UL33 (23), RCMV R33 (9), MCMV M33 (26), and HHV-6 and -7 U12 (33, 49). Both sequence and position of these genes within their respective genomes are conserved. Similar to the US28 family, GCRs of the UL33 family were shown to be related to chemokine receptors. Previously, we reported that the predicted amino acid sequences of UL33-like receptors share more similarity with mammalian chemokine receptors than with nonchemokine receptors (9). Moreover, Isegawa et al. (38) demonstrated that one member of the UL33 family of GCRs, HHV-6 U12, is a functional $\beta$-chemokine receptor capable of binding MIP1 $\alpha$, MIP1 $\beta$, RANTES, and MCP-1 (38). Although not much is known about the function of this chemokine receptor-like family, Margulies et al. detected the UL33 protein in both the membranes of HCMV-infected cells and the envelopes of HCMV virions (43a). Additionally, both RCMV R33 and MCMV M33 genes were shown to be essential for RCMV and MCMV replication in salivary glands of infected rats and mice, respectively $(9,26)$. A third group (the gammaherpesvirus GCR family) consists of seven gammaherpesvirus-encoded chemokine receptor-like genes: Epstein-Barr virus BILF1 (5, 25), HVS ECRF3 (48), KSHV ORF 74 (4), murine gammaherpesvirus 68 ORF 74 (63), and equine herpesvirus E1, E6, and E8 (57). In contrast to GCR genes of the US28 and UL33 family, sequences of the gammaherpesvirus GCR family are less well conserved. However, like GCR genes of the US28 and UL33 family, they show significant similarity with mammalian chemokine receptors $(4,26,48,57,63)$. The role of any of these GCRs in replication or persistence of gammaherpesviruses is unknown. To date, two members of this family have been studied in detail. The HVS ECRF3-encoded GCR was shown to be capable of binding $\alpha$ chemokines interleukin- 8 , GRO/MGSA, and NAP-2 (1). Another gammaherpesvirus-encoded GCR, the KSHV ORF 74 gene product, was demonstrated to bind both $\alpha$ (interleukin-8, MGSA, NAP-2, and PF-4) and $\beta$ (I-309 and RANTES) chemokines. In addition, the ORF 74 protein was found to be constitutively active (4),

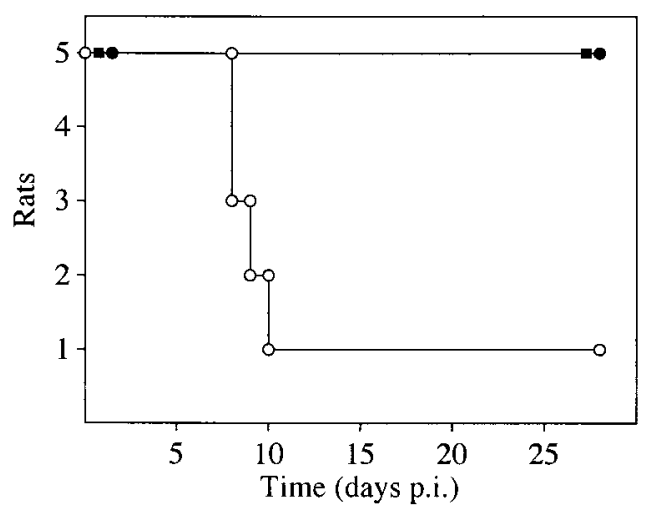

FIG. 9. The R78 gene plays a vital role in RCMV pathogenesis in vivo. The graph indicates survival of three groups of immunocompromised rats after intraperitoneal inoculation with $10^{6}$ PFU of either wt RCMV (O), RCMV $\Delta$ R78a $(\square)$, or RCMV $\Delta$ R78c $(\bullet)$. Survival was recorded up to day 28 p.i. 
having both oncogenic and angiogenic potential (7). A fourth, novel group of GCR genes (the UL78 family) comprises five betaherpesvirus ORFs that were recently recognized as putative GCR genes: HCMV UL78, RCMV R78, MCMV M78, and HHV-6 and -7 U51 (references 33, 49, and 54 and this report). Similar to the positions of GCR genes of the UL33 family, the positions of the UL78-like genes are conserved within betaherpesvirus genomes. However, in contrast to the sequences of the UL33-like genes, the sequences of the UL78 family are poorly conserved. The predicted amino acid sequences derived from the UL78-like genes significantly resemble neither chemokine receptors nor any other of the thousands of GCRs currently known. The assumption that UL78like genes are GCRs is based on three characteristics: (i) the presence of seven hydrophobic regions within the predicted amino acid sequences derived from all UL78-like genes (53); (ii) the presence of two cysteine residues within these amino acid sequences, which might be required for correct folding of the GCR polypeptide (53); and (iii) a stretch of amino acids within these amino acid sequences which bears similarity to a domain known to be required for $\mathrm{G}$ protein coupling (53). Consequently, the UL78 family is a novel class of orphan GCRs encoded by betaherpesviruses.

To investigate the role of the $\mathrm{R} 78$ gene in virus replication, RCMV strains in which the R78 gene is disrupted were constructed. These R78 deletion mutant strains were found to replicate 10 - to 100 -fold less efficiently than wt RCMV in fibroblasts and smooth muscle cells in vitro. By contrast, RCMV and MCMV strains that carry a deletion of the R33 and M33 gene, respectively, were previously found to replicate in vitro with efficiencies similar to those of the corresponding wt viruses $(9,26)$. A difference between these mutants and the R78 deletion mutants was also seen in vivo: both R33 and M33 deletion mutants were found to be impaired in replication in salivary glands of infected animals, whereas R78 deletion mutants were demonstrated to replicate as efficiently as wt RCMV in salivary glands. It is therefore likely that although both R33 and R78 putatively encode GCRs, these genes exert unrelated functions.

A lower efficiency of virus replication in vitro was observed not only after deletion of the complete R78 ORF from the RCMV genome but also after deletion of the region that encodes the putative R78 GCR C terminus. This putative intracellular part of the protein is therefore likely to be essential for the function of the $\mathrm{R} 78$ protein. The $\mathrm{C}$ terminus, like the DRL motif in the second intracellular domain of the $\mathrm{R} 78$ protein, might be essential for $\mathrm{G}$ protein coupling and signal transduction, similar to what was found for other GCRs (53).

The RCMV R78 gene plays an important part in the pathogenesis of virus infection in vivo. This was inferred from the lower mortality seen among immunocompromised rats infected with either RCMV $\Delta$ R78a or RCMV $\Delta$ R78c than among animals infected with wt virus. Although we did not find significant differences in virus replication between recombinant and wt viruses in vivo, it is possible that the decrease in virulence that is seen after disruption of the R78 gene of RCMV is correlated with the observation that both RCMV R78a and RCMV $\Delta \mathrm{R} 78 \mathrm{c}$ replicate less efficiently in fibroblasts and smooth muscle cells in vitro than wt virus. Similar to the R78 gene, the R33 GCR-like gene was reported to have a vital function in the pathogenesis of RCMV infection (9). It is likely that the HCMV counterparts of these genes (UL78 and UL33, respectively) have similar, important functions in the pathogenesis of HCMV infections in humans. The gene products of both UL78 and UL33 can therefore be considered as potential targets for future development of novel antiviral strategies.
The two recombinant RCMV strains described in this report induce syncytium formation in infected fibroblasts in vitro. Previously, syncytium formation has been observed in many different cell types infected with a variety of herpesvirus species: HCMV-infected human amnion cells (28), varicella-zoster virus-infected human melanoma cells (34), Epstein-Barr virus-superinfected Raji cells (8), HHV-6-infected human primary fetal astrocytes (35), HHV-7-infected T lymphocytes (56), and RCMV-infected Rat 2 cells (11). In these cases, syncytium formation appears to be associated with the cell type or MOI, since the same virus strains fail to produce these syncytium (syn) phenotypes upon infection of other permissive cell lines $(8,28,34,35)$ or after infection at lower titers $(8,56)$. Well-defined syn loci were found within genomes of a limited number of herpesvirus species, in particular within the genomes of herpes simplex type 1 (HSV-1) strains: UL20 (6), UL24 (40), UL27-gB (29), and UL53-gK (37). Some HCMV genes were likewise associated with syncytium formation. Syncytia are produced in human glioblastoma cells that constitutively express HCMV UL55-gB (59). Additionally, the chemokine receptor encoded by HCMV US28 was shown to enhance cell-cell fusion in cells constitutively expressing retroviral envelope glycoproteins (52). The recombinant RCMV strains RCMV $\Delta \mathrm{R} 78 \mathrm{a}$ and RCMV $\Delta \mathrm{R} 78 \mathrm{c}$ are the first syn mutant CMVs reported. We postulate that functional R78-encoded GCRs transduce signals to the cellular interior, thereby creating an intracellular environment essential for the formation of protein complexes to establish intercellular junctions. In HCMV- and HSV-1-infected cells, these cell-to-cell junctions are basically composed of viral glycoproteins $(27,36,43)$. Since many syn mutations are localized in HSV glycoprotein genes $(29,37)$, syncytia could be generated as a result of destabilized cell-to-cell contacts. The putative GCR encoded by R78 may mediate stabilization of glycoprotein complexes, directly by association with these glycoprotein complexes, or indirectly, through signal transduction to establish cell-to-cell contacts. These possible mechanisms for the function of the R78 gene product will have to be addressed in future studies.

\section{ACKNOWLEDGMENTS}

We thank Erik Beuken for cloning and sequencing of RCMV DNA. We also thank Joanne van Dam, Suzanne Kaptein, and Marjorie Nelissen for processing rat organs, Jos Broers for generating the confocal laser scan micrographs, and Rien Blok for critically reading the manuscript.

\section{REFERENCES}

1. Ahuja, S. K., and P. M. Murphy. 1993. Molecular piracy of mammalian interleukin- 8 receptor type B by herpesvirus saimiri. J. Biol. Chem. 268: 20691-20694.

2. ALIGN Query. 1 January 1997, posting date. [Online.] ALIGN program. Genestream, Institut de Génétique Humaine, Montpellier, France. http: //www2.igh.cnrs.fr/bin/align-guess.cgi. [11 January 1999, last date accessed.]

3. An, S., T. Bleu, O. G. Hallmark, and E. J. Goetzl. 1998. Characterization of a novel subtype of human $\mathrm{G}$ protein-coupled receptor for lysophosphatidic acid. J. Biol. Chem. 273:7906-7910.

4. Arvanitakis, L., E. Geras-Raaka, A. Varma, M. C. Gershengorn, and E. Cesarman. 1997. Human herpesvirus KSHV encodes a constitutively active G-protein-coupled receptor linked to cell proliferation. Nature 385:347-350.

5. Baer, R. J., A. T. Bankier, M. D. Biggin, P. L. Deininger, P. J. Farrell, T. J. Gibson, G. F. Hatful, G. S. Hudson, S. C. Satchwell, C. Sequin, P. S. Tuffnell, and B. G. Barrell. 1984. DNA sequence and expression of the B95-8 EpsteinBarr virus genome. Nature 310:207-211.

6. Baines, J. D., P. L. Ward, G. Campadelli-Fiume, and B. Roizman. 1991. The UL20 gene of herpes simplex virus 1 encodes a function necessary for viral egress. J. Virol. 65:6414-6424.

7. Bais, C., B. Santomasso, O. Coso, L. Arvanitakis, E. Geras Raaka, J. S. Gutkind, A. S. Asch, E. Cesarman, M. C. Gerhengorn, and E. A. Mesri. 1998 G-protein-coupled receptor of Kaposi's sarcoma-associated herpesvirus is a viral oncogene and angiogenesis activator. Nature 391:86-89. 
8. Bayliss, G. J., and H. Wolf. 1981. An Epstein-Barr virus early protein induces cell fusion. Proc. Natl. Acad. Sci. USA 78:7162-7165.

9. Beisser, P. S., C. Vink, J. G. van Dam, G. Grauls, S. J. Vanherle, and C. A. Bruggeman. 1998. The R33 G protein-coupled receptor gene of rat cytomegalovirus plays an essential role in the pathogenesis of viral infection. J. Virol. 72:2352-2363.

10. Beisser, P. S., S. J. F. Kaptein, E. Beuken, C. A. Bruggeman, and C. Vink. 1998. The Maastricht strain and England strain of rat cytomegalovirus represent different betaherpesvirus species rather than strains. Virology 245: 341-351.

11. Beisser, P. S., C. A. Bruggeman, and C. Vink. Unpublished data.

12. Beuken, E., R. Slobbe, C. A. Bruggeman, and C. Vink. 1996. Cloning and sequence analysis of the genes encoding DNA polymerase, glycoprotein B, ICP 18.5 and major DNA-binding protein of rat cytomegalovirus. J. Gen. Virol. 77:1559-1562.

13. Beuken, E., C. A. Bruggeman, and C. Vink. Unpublished data.

14. Billstrom, M. A., G. L. Johnson, N. J. Avdi, and G. S. Scott Worthen. 1998. Intracellular signalling by the chemokine receptor US28 during human cytomegalovirus infection. J. Virol. 72:5535-5544.

15. Bodaghi, B., T. R. Jones, D. Zipeto, C. Vita, L. Sun, L. Laurent, F. ArenzanaSeisdedos, J. Virelizier, and S. Michelson. 1998. Chemokine sequenstration by viral chemoreceptors as a novel viral escape strategy: withdrawal of chemokines from the environment of cytomegalovirus-infected cells. J. Exp. Med. 188:855-866.

16. Brown, T. 1993. Analysis of DNA sequences by blotting and hybridization, p. 4.2.1-4.2.15. In F. M. Ausubel, R. Brent, R. E. Kingston, D. D. Moore, J. G. Seidman, J. A. Smith, and K. Struhl (ed.), Current protocols in molecular biology. John Wiley \& Sons, Inc., New York, N.Y.

17. Brown, T., and K. Mackey. 1997. Analysis of RNA by Northern and slot blot hybridization, p. 4.9.1-4.9.16. In F. M. Ausubel, R. Brent, R. E. Kingston, D. D. Moore, J. G. Seidman, J. A. Smith, and K. Struhl (ed.), Current protocols in molecular biology. John Wiley \& Sons, Inc., New York, N.Y.

18. Bruggeman, C. A., H. Meijer, P. H. J. Dormans, W. H. M. Debie, G. E. L. M. Grauls, and C. P. A. van Boven. 1982. Isolation of a cytomegalovirus-like agent from wild rats. Arch. Virol. 73:231-241.

19. Bruggeman, C. A., H. Meijer, F. Bosman, and C. P. A. van Boven. 1985. Biology of rat cytomegalovirus infection. Intervirology 24:1-9.

20. Bruning, J., W. H. M. Debie, P. H. J. Dormans, H. Meijer, and C. A. Bruggeman. 1987. The development and characterization of monoclonal antibodies against rat cytomegalovirus induced agents. Arch. Virol. 94:5570 .

21. Cao, J. X., P. D. Gershon, and D. N. Black. 1995. Sequence analysis of HindIII Q2 fragment of capripoxvirus reveals a putative gene encoding a G-protein-coupled chemokine receptor homologue. Virology 209:207-212.

22. Chee, M. S., A. T. Bankier, S. Beck, R. Bohni, C. M. Brown, R. Cerny, T. Horsnell, C. A. Hutchison III, T. Kouzarides, J. A. Martignetti, E. Preddie, S. C. Satchwell, P. Tomlinson, K. M. Weston, and B. G. Barrell. 1990. Analysis of the protein-coding content of the sequence of human cytomegalovirus strain AD169. Curr. Top. Microbiol. Immunol. 154:125-169.

23. Chee, M. S., S. C. Satchwell, E. Preddie, K. M. Weston, and B. G. Barrell. 1990. Human cytomegalovirus encodes three $G$ protein-coupled receptor homologues. Nature 344:774-777.

24. Damoiseaux, J. G. M. C., E. A. Döpp, W. Calame, D. Chao, G. G. MacPherson, and C. D. Dijkstra. 1994. Rat macrophage lysosomal membrane antigen recognized by monoclonal antibody ED1. Immunology 83:140-147.

25. Davis-Poynter, N. J., and H. E. Farrell. 1996. Masters of deception: a review of herpesvirus immune evation strategies. Immunol. Cell Biol. 74:513-522.

26. Davis-Poynter, N. J., D. M. Lynch, H. Vally, G. R. Shellam, W. D. Rawlinson, B. G. Barrell, and H. E. Farrell. 1997. Identification and characterization of a $\mathrm{G}$ protein-coupled receptor homolog encoded by murine cytomegalovirus. J. Virol. 71:1521-1529.

27. Dingwell, K. S., C. R. Brunetti, R. L. Hendricks, Q. Tang, M. Tang, A. J. Rainbow, and D. C. Johnson. 1994. Herpes simplex virus glycoproteins E and I facilitate cell-to-cell spread in vivo and across junctions of cultured cells. J. Virol. 68:834-845.

28. Figueroa, M. E., L. Geder, and F. Rapp. 1978. Infection of human amnion cells with cytomegalovirus. J. Med. Virol. 2:369-375.

29. Gage, P. J., M. Levine, and J. C. Glorioso. 1993. Syncytium-inducing mutations localize to two discrete regions within the cytoplasmic domain of herpes simplex virus type 1 glycoprotein B. J. Virol. 67:2191-2201.

30. Gao, J. L., and P. M. Murphy. 1994. Human cytomegalovirus open reading frame US28 encodes a functional beta chemokine receptor. J. Biol. Chem. 269:28539-28542

31. Gao, J. L., D. B. Kuhns, H. L. Tiffany, D. McDermott, X. Li, U. Franke, and P. M. Murphy. 1993. Structure and functional expression of the human macrophage inflammatory protein $1 \alpha /$ RANTES receptor. J. Exp. Med. 177: 1421-1427.

32. Gerszten, R. E., J. Chen, M. Ishii, K. Ishii, T. Nanevicz, C. W. Turck, T. H. Vu, and S. R. Coughlin. 1994. Thrombin receptor's specificity for agonist peptide is determined by its extracellular surface. Nature 368:648-651.

33. Gompels, U. A., J. Nicholas, G. Lawrence, M. Jones, B. J. Thomson, M. E. Martin, S. Efstathiou, M. Craxton, and H. A. Macaulay. 1995. The DNA sequence of human herpesvirus-6: structure, coding content and genome evolution. Virology 209:29-51.

34. Harson, R., and C. Grose. 1995. Egress of varicella-zoster virus from the melanoma cell: a tropism for the melanocyte. J. Virol. 69:4994-5010.

35. He, J., M. McCarthy, Y. Zhou, B. Chandran, and C. Wood. 1996. Infection of primary human fetal astrocytes by human herpesvirus 6. J. Virol. 70:12961300 .

36. Huber, M. T., and T. Compton. 1998. The human cytomegalovirus UL74 gene encodes the third component of the glycoprotein H-glycoprotein Lcontaining envelope complex. J. Virol. 72:8191-8197.

37. Hutchinson, L., K. Goldsmith, D. Snoddy, H. Ghosh, F. L. Graham, and D. C. Johnson. 1992. Identification and characterization of a novel herpes simplex virus glycoprotein, gK, involved in cell fusion. J. Virol. 66:5603-5609.

38. Isegawa, Y., Z. Ping, K. Nakano, N. Sugimoto, and K. Yamanishi. 1998. Human herpesvirus 9 open reading frame U12 encodes a functional $\beta$-chemokine receptor. J. Virol. 72:6104-6112.

39. ISREC WU-BLAST server. 3 June 1999, revision date. [Online.] BLAST program, version 2.0. ISREC Bioinformatics Group, Swiss Institute of Bioinformatics, Geneva, Switzerland. http://www.ch.embnet.org/software /WUBLAST_form.html. [11 January 1999, last date accessed.]

40. Jacobson, J. G., S. L. Martin, and D. M. Coen. 1989. A conserved open reading frame that overlaps the herpes simplex virus thymidine kinase gene is important for viral growth in cell culture. J. Virol. 63:1839-1843.

41. Kozak, M. 1987. An analysis of 5'-noncoding sequences from 699 vertebrate messenger RNAs. Nucleic Acids Res. 15:8125-8148.

42. Kuhn, D. E., C. J. Beall, and P. E. Kolattukudy. 1995. The cytomegalovirus US28 protein binds multiple CC chemokines with high affinity. Biochem. Biophys. Res. Commun. 211:325-330.

43. Laquerre, S., R. Argnani, D. B. Anderson, S. Zucchini, R. Manservigi, and J. C. Glorioso. 1998. Heparan sulfate proteoglycan binding by herpes simplex virus type 1 glycoproteins $\mathrm{B}$ and $\mathrm{C}$, which differ in their contributions to virus attachment, penetration, and cell-to-cell spread. J. Virol. 72:6119-6130.

43a.Margulies, B. J., H. Browne, and W. Gibson. 1996. Identification of the human cytomegalovirus $\mathrm{G}$ protein-coupled receptor homologue encoded by UL33 in infected cells and enveloped virus particles. Virology 225:111-125.

44. Massung, R. F., V. Jayarama, and R. W. Moyer. 1993. DNA sequence analysis of conserved and unique regions of swinepox virus: identification of genetic elements supporting phenotypic observations including a novel $\mathrm{G}$ protein-coupled receptor homologue. Virology 197:511-528.

45. Meijer, H., J. C. Dreesen, and C. P. van Boven. 1986. Molecular cloning and restriction endonuclease mapping of the rat cytomegalovirus genome. J. Gen. Virol. 67:1327-1342.

46. Myers, E. W., and W. Miller. 1988. Optimal alignments in linear space. Comput. Appl. Biosci. 4:11-17.

47. Neote, K., D. DiGregorio, J. Y. Mak, R. Horuk, and T. J. Schall. 1993. Molecular cloning, functional expression, and signaling characteristics of a C-C chemokine receptor. Cell 72:415-425.

48. Nicholas, J., K. R. Cameron, and R. W. Honess. 1992. Herpesvirus saimiri encodes homologues of $\mathrm{G}$ protein-coupled receptors and cyclins. Nature 355:362-365.

49. Nicholas, J. 1996. Determination and analysis of the complete nucleotide sequence of human herpesvirus 7. J. Virol. 70:5975-5989.

50. Orlandi, A., H. Paul Ehrlich, P. Ropraz, L. G. Spagnioli, and G. Gabbiani. 1994. Rat aortic smooth muscle cells isolated from different layers and different times after endothelial denudation show distinct biological features in vitro. Arterioscler. Thromb. 14:982-989.

51. Parente, M. G., L. C. Chung, J. Ryynanen, D. T. Woodley, K. W. Wynn, E. A. Bauer, M. G. Mattei, M.-L. Chu, and J. Uitto. 1991. Human type VII collagen: cDNA cloning and chromosomal mapping of the gene. Proc. Natl. Acad. Sci. USA 88:6931-6935.

52. Pleskoff, O., C. Tréboute, and M. Alizon. 1998. The cytomegalovirus-encoded chemokine receptor US28 can enhance cell-cell fusion mediated by different viral proteins. J. Virol. 72:6389-6397.

53. Probst, W. C., L. A. Snyder, D. I. Schuster, J. Brosius, and S. C. Sealfon. 1992. Sequence alignment of the G-protein coupled receptor superfamily. DNA Cell Biol. 11:1-20.

54. Rawlinson, W. D., H. E. Farrell, and B. G. Barrell. 1996. Analysis of the complete DNA sequence of murine cytomegalovirus. J. Virol. 70:8833-8849.

55. Stals, F. S., F. Bosman, C. P. van Boven, and C. A. Bruggeman. 1990. An animal model for therapeutic intervention studies of CMV infection in the immunocompromised host. Arch. Virol. 114:91-107.

56. Secchiero, P., Z. N. Berneman, R. C. Gallo, and P. Lusso. 1994. Biological and molecular characteristics of human herpesvirus 7: in vitro growth optimalization and development of a syncytia inhibition test. Virology 202:506512.

57. Telford, E. A., M. S. Watson, H. C. Aird, J. Perry, and A. J. Davison. 1995. The DNA sequence of equine herpesvirus 2. J. Mol. Biol. 249:520-528.

58. TMpred-Prediction of Transmembrane Regions and Orientation. 3 June 1999, revision date. [Online.] TMpred program. ISREC Bioinformatics Group, Swiss Institute of Bioinformatics, Geneva, Switzerland. http://www .ch.embnet.org/software/TMPRED_form.html. [11 January 1999, last date accessed.] 
59. Tugizov, S., Y. Wang, I. Qadri, D. Navarro, E. Maidji, and L. Pereira. 1995. Mutated forms of human cytomegalovirus glycoprotein B are impaired in inducing syncytium formation. Virology 209:580-591.

60. Vossen, R. C. R. M., J. G. Derhaag, M. E. P. Slobbe-van Drunen, A. M. Duijvestijn, M. C. E. van Dam-Mieras, and C. A. Bruggeman. 1996. A dual role for endothelial cells in cytomegalovirus infection? A study of cytomegalovirus infection in a series of rat endothelial cell lines. Virus Res. 46:65-74.

61. Vink, C., E. Beuken, and C. A. Bruggeman. 1996. Structure of the rat cytomegalovirus genome termini. J. Virol. 70:5221-5229.

62. Vink, C., E. Beuken, and C. A. Bruggeman. Unpublished results.

63. Virgin, H. W., IV, P. Latreille, P. Wamsley, K. Hallsworth, K. E. Weck, A. J. Dal Canto, and S. H. Speck. 1997. Complete sequence and genomic analysis of murine gammaherpesvirus 68. J. Virol. 71:5894-5904.

64. Wilson, R., R. Ainscough, K. Anderson, C. Baynes, M. Berks, J. Bonfield, J. Burton, M. Connell, T. Copsey, J. Cooper, A. Coulson, M. Craxton, S.
Dear, Z. Du, R. Durbin, A. Favello, L. Fulton, A. Gardner, P. Green, T. Hawkins, L. Hillier, M. Jier, L. Johnston, M. Jones, J. Kershaw, J. Kirsten, N. Laister, P. Latreille, J. Lightning, C. Lloyd, A. McMurray, B. Mortimore, M. O'Callaghan, J. Parsons, C. Percy, L. Rifken, A. Roopra, D. Saunders, R. Shownkeen, N. Smaldon, A. Smith, E. Sonnhammer, R. Staden, J. Sulston, J. Thierry-Mieg, K. Thomas, M. Vaudin, K. Vaughan, R. Waterston, A. Watson, L. Weinstock, J. Wilkinson-Sproat, and P. Wohldman. 1994. 2.2 Mb of contiguous nucleotide sequence from chromosome III of C. elegans. Nature 368:32-38.

65. Xu, M., and R. V. Lewis. 1990. Structure of a protein superfiber: spider dragline silk. Proc. Natl. Acad. Sci. USA 87:7120-7124.

66. Yasuda, K., K. Raynor, H. Kong, C. D. Breder, J. Takeda, T. Reisine, and G. I. Bell. 1993. Cloning and functional comparison of kappa and delta opioid receptors from mouse brain. Proc. Natl. Acad. Sci. USA 90:67366740. 